\title{
A PRODUÇÃO DO CONHECIMENTO EM FONOAUDIOLOGIA EM COMUNICAÇÃO SUPLEMENTAR E/OU ALTERNATIVA: ANÁLISE DE PERIÓDICOS
}

\author{
Knowledge production in speech therapy on augmentative \\ and alternative communication: survey on journals
}

\author{
Ana Paula Berberian (1), Simone Krüger (2), Ana Cristina Guarinello (3), \\ Giselle Aparecida de Athayde Massi ${ }^{(4)}$
}

\section{RESUMO}

Tema: a Fonoaudiologia vem utilizando os recursos da Comunicação Suplementar e/ou Alternativa (CSA) para proporcionar maior autonomia a pessoas com limitações significativas da linguagem oral. Seu uso vem lentamente se expandindo no Brasil, mas ainda não constitui prática de amplo conhecimento na área da Fonoaudiologia. Objetivo: analisar a produção do conhecimento acerca da CSA publicada em periódicos especializados da área da Fonoaudiologia, no período entre 1997 e 2005. Conclusão: chega-se à conclusão que um panorama mais completo da produção científica em CSA se faz necessário com uma futura análise da produção do conhecimento acerca da CSA em outras áreas que desenvolvem estudos sobre essa temática, como na Pedagogia, Terapia Ocupacional, Fisioterapia, Psicologia, dentre outras.

DESCRITORES: Auxiliares de Comunicação para Deficientes; Comunicação e Divulgação Científica; Índice de Periódicos

\section{INTRODUÇÃO}

O aumento da produção científica em nosso país tem levado diversas áreas a realizarem periodicamente uma análise das tendências e características de tal produção, enfocando, especialmente, estudos e pesquisas que vem sendo divulgados a partir de sua publicação. Este tipo de análise

(1) Fonoaudióloga; Docente do Programa de Mestrado e Doutorado em Distúrbios da Comunicação da Universidade Tuiuti do Paraná, UTP, Curitiba PR; Doutora em História pela Pontifícia Universidade Católica de São Paulo.

(2) Fonoaudióloga; Universidade Tuiuti do Paraná, UTP, Curitiba PR; Mestranda em Distúrbios da Comunicação pela Universidade Tuiuti do Paraná.

(3) Fonoaudióloga; Docente do Programa de Mestrado e Doutorado em Distúrbios da Comunicação da Universidade Tuiuti do Paraná, UTP, Curitiba PR; Doutora em Linguística pela Universidade Federal do Paraná.

(4) Fonoaudióloga; Docente do Programa de Doutorado e Mestrado em Distúrbios da Comunicação da Universidade Tuiuti do Paraná, UTP, Curitiba PR; Doutora em Linguística pela Universidade Federal do Paraná.

Conflito de interesse: inexistente permite delinear um panorama histórico da produção do conhecimento numa determinada área e oferece informações necessárias para o seu implemento. Se é fundamental o aumento quantitativo e qualitativo das produções científicas, é imprescindível a divulgação de tais conhecimentos para que efetivamente possam estes tornar-se disponíveis à sociedade em geral, e à comunidade científica, em particular, dessa forma cumprindo seu papel transformador ${ }^{1}$.

É fato internacionalmente reconhecido que, dentre os principais parâmetros para a mensuração do vigor científico de uma determinada área, encontram-se o volume de artigos publicados em periódicos indexados em bases de dados e o número de citações que recebem, registrados nesses mesmos veículos ${ }^{2}$.

Nessa medida, considerando a importância dos veículos de divulgação desses conhecimentos, os periódicos assumem lugar de destaque, uma vez que aglutinam, de forma dinâmica, parte significativa da produção do conhecimento científico. Os periódicos são veículos velozes e potencialmente 
de maior visibilidade, caso estejam indexados em bases de dados significativas na área do saber a que se destinam. Além de serem aglutinadores, têm papel fundamental de definirem critérios de qualidade para a organização estrutural e metodológica de uma determinada produção, possibilitando uma avaliação da qualidade e rigor científico da pesquisa ${ }^{1}$.

A exemplo de outras áreas, a Fonoaudiologia vem desenvolvendo estudos que visam a análise da produção do conhecimento, especialmente, a partir de recortes temáticos ${ }^{3-5}$.

Estudos da área fonoaudiológica afirmam a importância desta análise como condição para a área identificar os domínios de investigação predominantes e, a partir daí, delinear novas propostas de pesquisa e intervenção ${ }^{6}$.

Este estudo versa sobre a produção do conhecimento em Comunicação Suplementar e/ou Alternativa (CSA) na área da Fonoaudiologia, uma vez que a área vem gradativamente ampliando a utilização dos recursos da CSA para proporcionar maior autonomia a pessoas com limitações significativas da linguagem oral.

Estudos apontam para o fato de que o uso dos recursos da CSA vem lentamente se expandindo no Brasil. Esses estudos também têm evidenciado a necessidade de um avanço na produção de conhecimento nesse campo, uma vez que o mesmo ainda é pouco explorado e difundido em nosso país ${ }^{7}$.

Ressalta-se a importância desses recursos, bem como, de estudos relativos aos mesmos, uma vez que a CSA, enquanto conjunto de instrumentos que permitem a "fala" não-oralizada, a "fala" dita no "apontar" dos sinais gráficos, representa uma maneira de ampliar as possibilidades de sujeitos com limitações significativas de oralidade desenvolverem a sua linguagem. Considerada como um recurso linguístico mediador dos processos de apropriação da linguagem, a CSA reúne material gráfico, entre eles conjuntos de sinais gráficos (PCS - Picture Communication Symbols, BLISS, PIC - Pictogram Ideogram Communication etc), desenhos, fotos, palavra escrita, alfabeto e ainda compreende uma série de estratégias na elaboração e acesso aos sinais gráficos dispostos em pranchas de comunicação ${ }^{8}$.

Estudos sinalizam para a efetividade do uso da CSA na escola, pois pode ser instrumento mediador do processo de aprendizagem do aluno sem fala articulada e permite que esse aluno torne-se interlocutor mais ativo no processo de aprendizagem ${ }^{9}$. Nesse contexto, a CSA coloca-se como um recurso significativo para a inclusão escolar e social, uma vez que contribui para que os sujeitos passem de espectadores a "falantes do apontar". Além de torná-los participantes, os recursos da CSA proporcionam melhora na interação do aluno não falante com o professor e demais alunos, pois esses passam a expressar suas opiniões e a realizar escoIhas em sala de aula ${ }^{9,10}$.

O objetivo do presente levantamento é analisar parte da produção do conhecimento acerca da Comunicação Suplementar e/ou Alternativa (CSA), veiculada em periódicos especializados da área da Fonoaudiologia, editados no período entre 1997 e 2005.

\section{MÉTODOS}

Foram analisados os seguintes periódicos especializados em Fonoaudiologia, com circulação nacional: Revista CEFAC (CEFAC), desde a sua primeira edição em 1999, até 2005; Revista de Distúrbios da Comunicação (DIC), desde 1997, até 2005; Revista da Sociedade Brasileira de Fonoaudiologia (SBFa); desde 1997 até 2005; Fono Atual (Fonoatual), desde 1997 até 2005; Pró-Fono: revista de atualização científica (Pró-Fono), desde 1997 até 2005.

O procedimento da coleta de dados ocorreu a partir da identificação do volume, ano e número das edições no período de 1997 a 2005. Após essa etapa procedeu-se a seleção dos artigos acerca da CSA, bem como o mapeamento das características de cada artigo. Após tal procedimento, realizou-se uma síntese de cada artigo, contendo objetivos, resultados e conclusão.

Foram selecionadas as seguintes variáveis para o mapeamento das características:

- Tipo de produção: foram considerados relato de caso e revisão de literatura, tendo em vista serem apenas esses os tipos de produção utilizados.

- Temática: foram consideradas as subáreas linguagem oral e linguagem escrita, sendo estas duas, apenas as subáreas abordadas. Essa classificação permite respostas múltiplas.

- Faixa etária dos sujeitos de pesquisa: foram subdivididas as faixas de 0 a 3 meses, 4 meses a 3 anos, 3 anos a 10 anos, 10 anos a 16 anos, 16 anos a 35 anos, 35 anos a 65 anos e acima de 65 anos. Essa classificação também permite respostas múltiplas;

- Tipo de intervenção: foram selecionados procedimentos de triagem, prevenção, diagnóstico/ avaliação, terapia individual, terapia em grupo;

- Contexto Institucional: foram selecionados clínica, escola, centro de reabilitação. O contexto institucional refere-se ao contexto que está sendo abordado e não ao local de coleta de dados. Essa classificação permite respostas múltiplas. 
Quadro clínico apresentado pelos sujeitos pesquisados: sujeitos portadores de paralisia cerebral e sujeitos com problemas neurológicos não definidos.

Autoria: foram considerados o número de autores, a formação dos mesmos, a sua vinculação com Instituição de Ensino Superior (IES), bem como a localização geográfica das mesmas.

Ressalta-se ainda que todos os artigos foram lidos em sua totalidade e que a partir dessa leitura foi realizada uma apresentação dos mesmos contendo: título, nome dos autores, objetivo, resultado e conclusão.

\section{REVISÃO DA LITERATURA}

Nas Tabelas 1 e 2 e na Figura 1 apresenta-se um panorama do número de fascículos de periódicos de Fonoaudiologia e artigos publicados no período de 1997 a 2005.

Considerando os percentuais relativos ao total de fascículos publicados no período de 1997 até 2005 demonstrados na Figura 1, a revista Pró-Fono obteve o percentual de 299 (25\%) das publicações, seguida da revista do CEFAC, com 264 (22\%) de publicações. A revista Fono Atual correspondeu a $237(19 \%)$ do total e, por último, a revista da SBFa

Tabela 1 - Total de fascículos editados no período de 1997 a 2005

\begin{tabular}{|c|c|c|c|c|c|c|c|c|c|c|c|}
\hline PERIÓDICOS & 1997 & 1998 & 1999 & 2000 & 2001 & 2002 & 2003 & 2004 & 2005 & TOTAL & Percentual \\
\hline SBFa & 2 & 2 & 2 & 2 & 2 & 2 & 2 & 4 & 4 & 22 & 18 \\
\hline CEFAC & - & - & 2 & 2 & 2 & 3 & 4 & 4 & 4 & 21 & 18 \\
\hline DIC & 2 & 2 & 2 & 2 & 2 & 2 & 3 & 3 & 3 & 21 & 18 \\
\hline Fonoatual & 3 & 3 & 4 & 4 & 4 & 4 & 4 & 4 & 4 & 34 & 28 \\
\hline Pró-Fono & 2 & 2 & 2 & 2 & 2 & 3 & 3 & 3 & 3 & 22 & 18 \\
\hline TOTAL & 9 & 9 & 12 & 12 & 12 & 14 & 16 & 18 & 18 & 120 & 100 \\
\hline Percentual & 8 & 8 & 10 & 10 & 10 & 12 & 13 & 15 & 15 & 100 & \\
\hline
\end{tabular}

Tabela 2 - Número de artigos sobre CSA produzidos nos periódicos, entre 1997-2005

\begin{tabular}{lcccccccccc}
\hline PERIÓDICOS & 1997 & $\mathbf{1 9 9 8}$ & $\mathbf{1 9 9 9}$ & $\mathbf{2 0 0 0}$ & $\mathbf{2 0 0 1}$ & $\mathbf{2 0 0 2}$ & $\mathbf{2 0 0 3}$ & $\mathbf{2 0 0 4}$ & 2005 & TOTAL \\
\hline DIC & 0 & 5 & 0 & 0 & 0 & 0 & 0 & 0 & 0 & 5 \\
SBFa & 0 & 0 & 0 & 0 & 0 & 0 & 0 & 0 & 0 & 0 \\
Pró-Fono & 0 & 0 & 0 & 0 & 0 & 1 & 1 & 1 & 1 & 4 \\
Fonoatual & 0 & 0 & 1 & 0 & 0 & 0 & 0 & 0 & 0 & 1 \\
CEFAC & 0 & 0 & 0 & 0 & 0 & 0 & 0 & 0 & 1 & 1 \\
\hline TOTAL & 0 & 5 & 1 & 0 & 0 & 1 & 1 & 1 & 2 & 11 \\
\hline
\end{tabular}

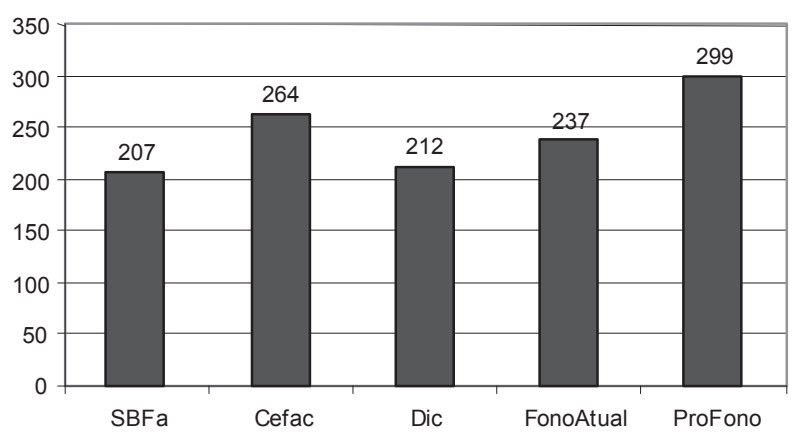

Figura 1 - Número de artigos produzidos pelas revistas DIC, SBFa, Pró-Fono, Fonoatual, CEFAC (1997- 2005) com 207 (16,98\%) e a DIC com 212 (17,39\%). A Figura 2 aponta a distribuição da produção do conhecimento em CSA em relação à distribuição ao tipo de produção.

Ressalta-se o fato de que os 11 artigos abordam a subárea linguagem oral e que um dos artigos de revisão de literatura trata também de linguagem escrita.

A Figura 3 mostra a faixa etária dos sujeitos pesquisados. Observa-se que, nas Figuras 3,4 e 5 os artigos sem identificação correspondem aqueles que não envolvem pesquisa de campo com seres humanos.

A Figura 4 ilustra a distribuição dos tipos de intervenções abordados nos artigos. 


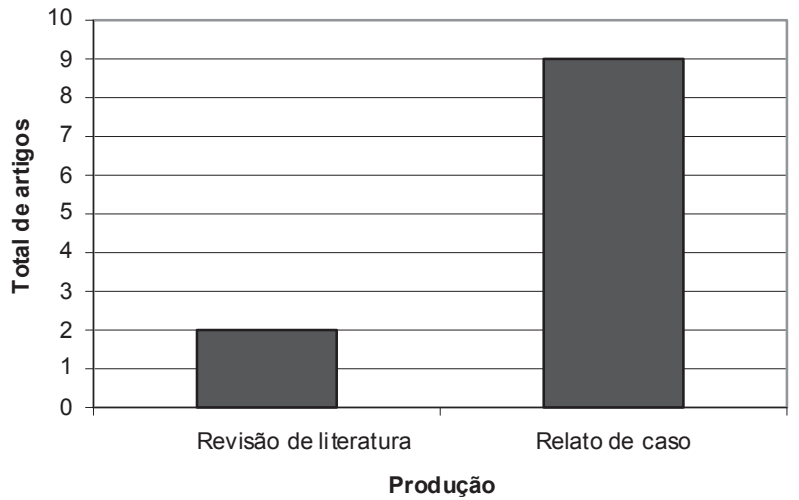

Figura 2 - Distribuição dos artigos segundo a variável tipo de produção

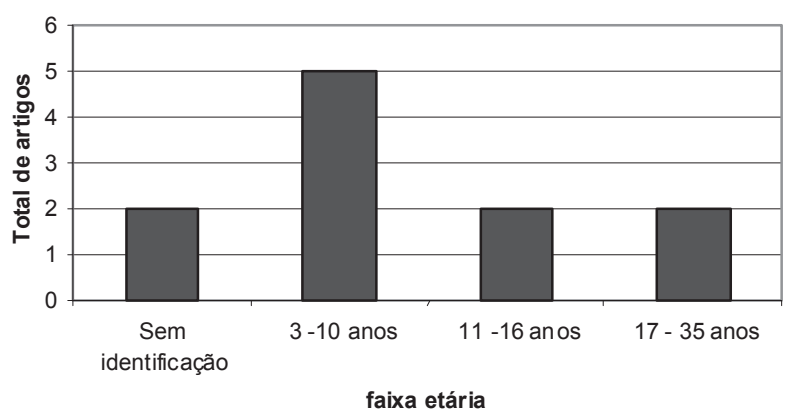

Figura 3 - Distribuição dos artigos segundo a variável faixa etária dos sujeitos pesquisados

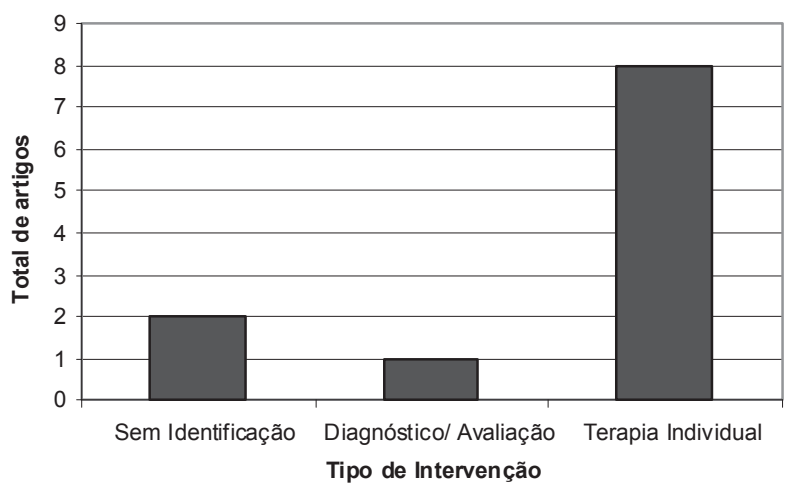

Figura 4-Distribuição temática quanto à variável tipo de intervenção

A Figura 5 explicita a distribuição dos artigos quanto aos contextos institucionais abordados.

Dos 11 artigos analisados, 2 artigos não explicitaram o contexto institucional, por serem revisões de literatura, discutindo características do recurso. Além disso, 3 artigos foram desenvolvidos em centros de reabilitação, mais especificamente na APAE, e 6 artigos em clínicas.

A Figura 6 apresenta a distribuição dos sujeitos pesquisados segundo a etiologia.

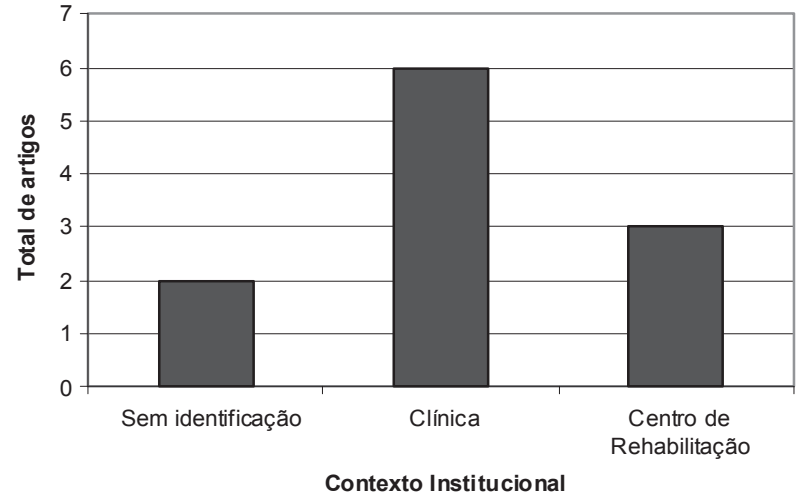

Figura 5-Distribuição temática quanto à variável contexto institucional

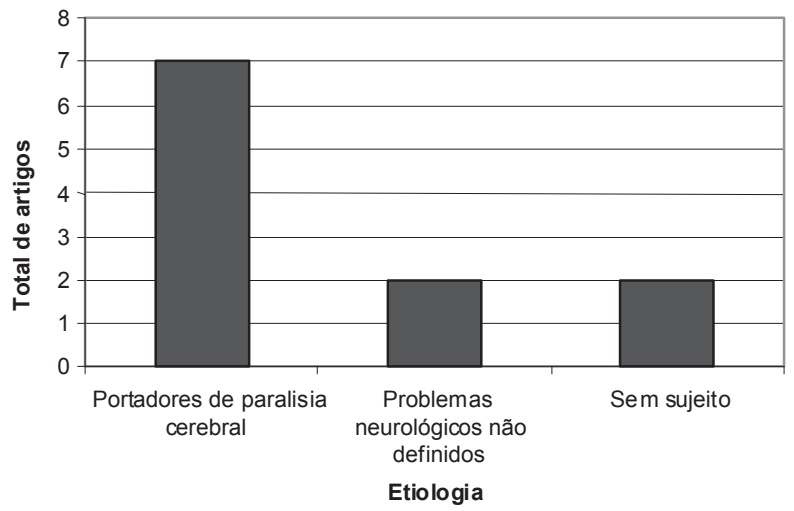

Figura 6 - Distribuição do quadro clínico quanto aos sujeitos pesquisados

$\mathrm{Na}$ Tabela 3 verifica-se a distribuição dos artigos pesquisados, quanto a formação dos autores, vínculos com IES e procedência geográfica das mesmas.

Os dados apresentados na Tabela 3 referem-se à vinculação dos autores a Instituições de Ensino Superior (IES), tanto na categoria docente quanto discente. Dos dados levantados quanto à procedência geográfica das instituições às quais os autores estão vinculados, verifica-se que o Estado de São Paulo apresenta porcentagem de cerca de 11 $(61,1 \%)$ da produção total. As demais regiões correspondem ao Rio de Janeiro, Espírito Santo, Santa Catarina e Canadá.

Quanto à formação dos autores dos artigos levantados, a grande maioria dos autores é composta de fonoaudiólogos $11(61,1 \%)$, por se tratar de uma análise da produção do conhecimento em CSA em periódicos de Fonoaudiologia. Em seguida, foram verificados 5 (27,7\%) psicólogos, 1 (5,5\%) analista de sistemas e um (5,5\%) sem identificação de sua formação acadêmica. 
Tabela 3 - Distribuição da produção em relação aos vínculos dos autores com IES e procedência geográfica

\begin{tabular}{lccc}
\hline Instituição de Ensino Superior (IES) & Docente & Discente & Total \\
\hline Universidade Federal de São Paulo - UNIFESP & 1 & - & 1 \\
\hline Universidade de São Paulo -USP & 4 & 1 & 5 \\
\hline USP - Bauru/SP & 1 & - & 1 \\
\hline Universidade Metodista de Piracicaba - UNIMEP & 1 & - & 1 \\
\hline Centro Universitário São Camilo - Espírito Santo - CUSC & 1 & - & 1 \\
\hline Faculdade Tecnológica de São Paulo - FATEC São Paulo & 1 & - & 1 \\
\hline Universidade Federal de São Carlos - UFSCar & 1 & - & 1 \\
\hline Pontifícia Universidade Católica de São Paulo PUC - SP & 1 & - & 1 \\
\hline Universidade do Estado do Rio de Janeiro - UERJ & 1 & - & 1 \\
\hline Universidade do Vale do Itajaí - UNIVALI & 1 & - & 1 \\
\hline IRDPQ - L'Institut de réadaptation en déficience physique de & 1 & - & 1 \\
Québec, Canadá & - & - & 3 \\
\hline Sem vínculo & & & 18 \\
\hline
\end{tabular}

Quanto à prevalência de vínculos dos autores com Instituições de Ensino Superior, a maioria dos autores está vinculada a IES localizadas nas regiões sudeste e sul do Brasil.
A seguir, está apresentada a síntese de cada um dos 11 artigos contendo: título, autores, objetivo, resultado e conclusão.

\begin{tabular}{|c|c|}
\hline tigo 1 & \\
\hline Título & "Codificação de mensagens picto-ideográficas em paralisia cerebral: Participação de processos verbais" \\
\hline Autores & Capovilla; Gonçalves; Macedo e Duduchi ${ }^{10}$ \\
\hline Síntese & $\begin{array}{l}\text { Esse trabalho, realizado no laboratório de Neuropsicolinguística Experimental Cognitiva do Instituto de } \\
\text { Psicologia da USP, com base numa perspectiva cognitivista analisou o caso de uma menina de } 13 \\
\text { anos, portadora de paralisia cerebral. Objetivou avaliar a eficiência de uma adaptação computadorizada, } \\
\text { desenvolvida por este laboratório, do sistema PIC, a partir da comparação da codificação de mensagens } \\
\text { do sistema PIC, sob estimulação visual (descrição de eventos observados) e auditiva (transcrição de } \\
\text { enunciados ouvidos). Concluiu-se que para o sujeito pesquisado foi mais fácil transcrever enunciados } \\
\text { ouvidos do que descrever eventos observados, fato atribuído à prática intensiva feita com voz digitalizada, } \\
\text { propiciando fonologicamente codificar as informações pictóricas do sistema de comunicação utilizado, } \\
\text { bem como o aumento da memória de trabalho. }\end{array}$ \\
\hline \multicolumn{2}{|r|}{ 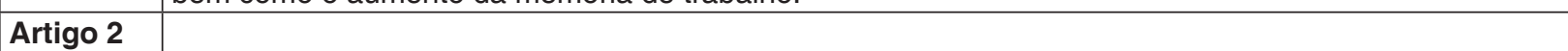 } \\
\hline Título & "Memória de trabalho em paralisia cerebral: primazia, recência e consolidação" \\
\hline Autores & Capovilla, Nunes e Macedo ${ }^{11}$ \\
\hline Síntese & $\begin{array}{l}\text { O estudo aborda o processamento de informações na memória com base no modelo de memória de } \\
\text { trabalho } 12 \text { sobre memória sensorial ecóica. A partir da utilização, por dois anos, do sistema de CSA } \\
\text { Imagoanavox, o objetivou de objetivou analisar o desempenho da memória de trabalho e a aquisição } \\
\text { de leitura e escrita em um paralítico cerebral sem fala articulada de } 15 \text { anos. Dois experimentos foram } \\
\text { realizados com o paciente: analise da memória de trabalho do sujeito pesquisado, em busca de evidências } \\
\text { de efeitos de primazia e recência; analise da natureza do ensaio subjacente à consolidação, ou seja, } \\
\text { se aberto ou encoberto, se visual ou subvocal. Os resultados evidenciaram que o sujeito portador de } \\
\text { paralisia cerebral não alfabetizado utiliza um componente da memória de trabalho }{ }^{12} \text { conhecido como } \\
\text { tábua de desenho viso-espacial; bem como procurava ser mais ativo diante de seu déficit de memória de } \\
\text { trabalho, adotando uma estratégia compensatória. }\end{array}$ \\
\hline
\end{tabular}




\begin{tabular}{|c|c|}
\hline Artigo 3 & \\
\hline Título & "Aprendendo símbolos Bliss via computador" \\
\hline Autores & Capovilla e Thiers ${ }^{13}$ \\
\hline Síntese & $\begin{array}{l}\text { Esse estudo realiza revisão da semantografia do sistema BLISS de comunicação, bem como a introdução } \\
\text { deste sistema em um sistema computadorizado de ensino de símbolos BLISS-IMAGOBLISSVOX. } \\
\text { Objetivou avaliar a eficácia do delineamento de ancoragem de símbolos BLISS a vocábulos (SV), figuras } \\
\text { (SF), e palavras escritas (SP). Avaliou-se o efeito do tipo de treino (SV, SF, SP) e do tipo de teste (SV, } \\
\text { SF, SP), analisando o desempenho no treino em termo de tempo médio e total e frequência de erros } \\
\text { e tentativas. No teste analisando a proporção de acerto, tempo médio de acerto, o sujeito pesquisado, } \\
\text { um adolescente de } 17 \text { anos portador de paralisia cerebral, não conseguia se comunicar através da fala } \\
\text { articulada. Conclui-se que a ordem de eficiência de treino e teste foi SV, SF, SP em todas as medidas. }\end{array}$ \\
\hline \multicolumn{2}{|l|}{ Artigo 4} \\
\hline Título & "Comunicação suplementar e alternativa: indicação para crianças portadoras de paralisia cerebral" \\
\hline Autores & Fernandes e Guedes ${ }^{14}$ \\
\hline Síntese & $\begin{array}{l}\text { O objetivo desse estudo era apresentar modos de comunicação e comportamentos comunicativos que } \\
\text { os participantes utilizavam para se expressar. A partir da explicitação da importância do uso da CSA em } \\
\text { portadores de paralisia cerebral, realiza uma avaliação com } 32 \text { portadores de PC. Concluiu-se que o modo } \\
\text { de comunicação mais utilizado era o da expressão facial e corporal. Dentre os } 32 \text { sujeitos pesquisados, } 7 \\
\text { emitiam palavras, ainda de difícil compreensão, devido a uma severa disartria. Para essas } 7 \text { crianças, a } \\
\text { indicação seria de comunicação suplementar. Para os } 25 \text { outros sujeitos pesquisados, a indicação seria } \\
\text { de comunicação alternativa. Os símbolos que se mostraram mais eficazes foram os do Sistema PCS }{ }^{15} \text {. }\end{array}$ \\
\hline \multicolumn{2}{|l|}{ Artigo 5} \\
\hline Título & "Introdução de comunicaçã \\
\hline Autores & Pires e Limongi ${ }^{16}$ \\
\hline Síntese & $\begin{array}{l}\text { O objetivo foi ressaltar aspectos a serem avaliados para a determinação do uso e da escolha do Sistema } \\
\text { CSA. O sujeito da pesquisa foi uma criança portadora de paralisia cerebral, com 6a. e 4m. A avaliação } \\
\text { foi realizada a partir do protocolo conforme LIF-SASM, enfocando o desenvolvimento neuropsicomotor; } \\
\text { o sistema miofuncional e a cognição. A partir de tal avaliação foi selecionado o Sistema BLISS, mas } \\
\text { antes o sujeito da pesquisa passou por intervenção terapêutica, trabalhando com aspectos cognitivos, } \\
\text { pré-requisitos para a introdução de tal sistema. O estudo foi realizado no Laboratório de Investigação } \\
\text { Fonoaudiológica de Síndromes e Alterações Sensório-Motoras (LIF-SASM) do Curso de Fonoaudiologia } \\
\text { da Faculdade de Medicina da USP. Concluiu-se que algumas noções são importantes para que o sujeito } \\
\text { passa-se a usar a CSA como suplementar. Pode-se constatar, ainda, que a permanência de objeto } \\
\text { e representação simbólica é um pré-requisito para a apresentação e o reconhecimento de símbolos } \\
\text { impressos, bem como a atenção visual é um pré-requisito para o uso efetivo dos símbolos. A noção } \\
\text { de igual e diferente é importante para a diferenciação dos símbolos e a classificação e seriação para } \\
\text { visualização dos símbolos que são dispostos em colunas na prancha. Introduzido o sistema de CSA } \\
\text { BLISS, não foi observada redução das emissões orais. }\end{array}$ \\
\hline \multicolumn{2}{|l|}{ Artigo 6} \\
\hline Título & "Adaptações do sistema de comunicação por troca de figuras no contexto escolar" \\
\hline Autores & Almeida, Piza e Lamônica ${ }^{17}$ \\
\hline Síntese & $\begin{array}{l}\text { Esse estudo objetivou avaliar a eficácia do sistema de comunicação, utilizando o método PECS } \\
\text { (intercâmbio de figuras) e o sistema PCS, junto à uma criança de 9a. e } 10 \mathrm{~m} \text {, portadora de paralisia } \\
\text { cerebral, a partir de sessões individuais. Apresentada uma definição da CSA e, também, do PECS, o } \\
\text { estudo apresenta resultados de sessões, nas quais utilizaram o sistema PECS- adaptado }{ }^{18} \text {, associado ao } \\
\text { PCS }{ }^{15} \text {. Conclui-se que tais recursos foram eficazes para que o sujeito pesquisado pudesse ser auxiliado } \\
\text { em sua comunicação, havendo aumento de emissão de sons, com o objetivo de obtenção de maior } \\
\text { atenção para si. Pode-se verificar, ainda, maiores interações comunicativas, aumento de solicitações e } \\
\text { maior facilidade em manter um diálogo simples e transmitir mensagens. }\end{array}$ \\
\hline \multicolumn{2}{|l|}{ Artigo 7} \\
\hline Título & "CSA, \\
\hline Autora & Chun $^{7}$ \\
\hline Síntese & $\begin{array}{l}\text { O estudo objetivou investigar a contribuição do sistema de CSA PCS para a apropriação da linguagem } \\
\text { de uma criança não falante. Inicialmente são abordadas questões de linguagem relativas a sujeitos com } \\
\text { distúrbios severos de articulação. Apresentando uma revisão histórica da CSA, enfatiza o uso dos sistemas } \\
\text { de CSA como instrumento de mediação, favorecendo o desenvolvimento da linguagem. Apresenta um } \\
\text { relato de caso de uma criança portadora de paralisia cerebral com 8a. Conclui-se que a introdução do PCS } \\
\text { foi um dos fatores que favoreceu o desenvolvimento da linguagem do sujeito pesquisado, ou seja, pode-se } \\
\text { verificar o papel preponderante do uso da CSA como instrumento de mediação semiótica, possibilitando } \\
\text { maior desenvolvimento linguístico e cognitivo e a constituição da identidade do sujeito como falante. }\end{array}$ \\
\hline
\end{tabular}




\begin{tabular}{|c|c|}
\hline Artigo 8 & \\
\hline Título & "O desenvolvimento da linguagem por meio do sistema pictográfico de comunicação" \\
\hline Autores & Trevizor e Chun ${ }^{19}$ \\
\hline Síntese & $\begin{array}{l}\text { O estudo visa investigar o uso do sistema PCS como instrumento de mediação, a partir de estudo de caso } \\
\text { de uma criança de } 8 \text { a., com comprometimento neurológico, de diagnóstico indefinido que apresentava } \\
\text { alteração significativa de linguagem oral. Apresenta a importância da linguagem, tanto para a constituição } \\
\text { do sujeito, quanto para o desenvolvimento das estruturas psicológicas superiores, de acordo com a } \\
\text { perspectiva vygotskyana. A partir de uma revisão breve da CSA no Brasil e dos fundamentos vygotskyanos } \\
\text { nos estudos da linguagem e na CSA, é apresentado o método e os procedimentos de adotados, ou } \\
\text { seja, foi realizada terapia individual. Concluiu-se que a construção de narrativas por meio de sistemas } \\
\text { pictográficos de comunicação, com a mediação de um adulto, levou a um favorecimento da linguagem } \\
\text { de sujeitos sem fala articulada. }\end{array}$ \\
\hline Artigo 9 & \\
\hline Título & $\begin{array}{l}\text { "Contribuições da CA de baixa tecnologia em paralíticos cerebrais sem comunicação oral: relato de um } \\
\text { caso" }\end{array}$ \\
\hline Autores & Miranda e Gomes ${ }^{20}$ \\
\hline Síntese & $\begin{array}{l}\text { O estudo objetivou descrever e comparar a comunicação de um portador de paralisia cerebral, sem } \\
\text { condições de expressão verbal, antes e após a implantação do sistema de comunicação alternativa } \\
\text { de baixa tecnologia. A partir da definição da CSA e da explicitação de sua importância, explicam os } \\
\text { diferentes recursos de alta e baixa tecnologia. A partir de estudo de caso de um paciente de } 21 \text { anos, } \\
\text { sexo masculino, portador de paralisia cerebral, com intervenção durante dois anos, pode-se constatar } \\
\text { que o uso da CSA de baixa tecnologia, nesse sujeito pesquisado, propiciou melhora em sua capacidade } \\
\text { de comunicação e, consequentemente, em sua condição escolar e social. }\end{array}$ \\
\hline Artigo 10 & \\
\hline Título & "Sistemas de comunicação alternativa e suplementar: princípios de engenharia e design" \\
\hline Autores & Capovilla, Macedo, Duduchi, Thiers ${ }^{21}$ \\
\hline Síntese & $\begin{array}{l}\text { O estudo objetivou explicar os Sistemas de Comunicação Alternativa, voltados para paralíticos cerebrais. } \\
\text { Para tanto, aborda as diferenças dos símbolos pictoriais e simbólicos e aspectos da engenharia, design } \\
\text { dos sistemas e os usos destes em sistemas de CSA associados a recursos de multimídia para desenvolver } \\
\text { comunicação via Internet. }\end{array}$ \\
\hline Artigo 11 & \\
\hline Título & "O uso de sistemas alternativos e facilitadores de comunicação nas afasias" \\
\hline Autores & Capovilla e Macedo 22 \\
\hline Síntese & $\begin{array}{l}\text { O estudo apresenta uma revisão sobre a evolução do uso de sistemas de CSA com pacientes afásicos. } \\
\text { Tem como objetivo apresentar os diferentes sistemas alternativos e facilitadores de comunicação em } \\
\text { afásicos. Esses sistemas têm uma função mais facilitadora do que alternativa e são indicados para } \\
\text { reaquisição de comunicação vocal e escrita e para auxiliar essa comunicação em contextos específicos do } \\
\text { cotidiano. Concluiu-se que sistemas computadorizados baseados em pictogramas e com voz digitalizada } \\
\text { são os mais indicados para afásicos. }\end{array}$ \\
\hline
\end{tabular}

Apesar do uso da CSA estar paulatinamente se expandindo em nosso país, tal recurso não se configura como um objeto de estudo priorizado pelos profissionais da área fonoaudiológica ${ }^{8}$.

Se, conforme resultados apresentados nas Tabelas 1 e 2 e Figura 1, verifica-se um avanço significativo da quantidade de produção geral no período estudado, tal aumento não ocorreu em se tratando da distribuição anual da produção em CSA. Além dos dados evidenciarem que não houve uma tendência de crescimento em relação a essa produção, a existência de apenas 11 artigos publicados sobre a referida temática permite afirmar que a quantidade da produção é absolutamente restrita, uma vez que representa menos de $1 \%$ do total da produção fonoaudiológica publicada nos referidos periódicos e período delimitados.
Quanto ao tipo de produção, constatou-se que dos 11 artigos levantados, $9(81,8 \%)$ referem-se a relatos de caso, configurando-se como o tipo de produção mais utilizado. Ressalta-se que esse tipo de produção versa sobre a intervenção clínica e, no caso específico, enfocou a utilização da CSA como recurso terapêutico. Os artigos de revisão de literatura, focados em aspectos teórico-metodológicos utilizados na CSA, também priorizam a inserção de tal recurso no atendimento de pacientes portadores de paralisia cerebral e afásicos, ou seja, como recurso terapêutico. A prevalência de artigos que abordam a clínica e, mais especificamente, o processo terapêutico individual pode ser constatada, também, na Figura 4 e nas sínteses dos artigos.

A exclusividade de análises da CSA como recurso terapêutico, permite compreender a ênfase 
de sua inserção no contexto clínico e nos centros de reabilitação, em contra partida à inexistência de estudos que a abordem no contexto familiar e/ ou educacional (Figura 5). Ressalta-se o fato de que a ausência de conhecimento produzido pela área que problematizem, dentre outros aspectos, a aceitação, os tipos de tecnologias, bem como, os modos, as frequências e finalidades de utilização nos contextos familiares e educacionais, apontam para a falta de elementos teórico-práticos para lidar com a complexidade de tal recurso. Razão pela qual, atualmente, a área encontra-se desprovida de conhecimentos próprios que permita compreender aspectos fundamentais que interferem no uso efetivo da CSA ${ }^{23}$. Em relação ao perfil da população estudada, pode-se verificar a ênfase de sujeitos na faixa etária de 3-10 anos (Figura 3) e com encefalopatia crônica infantil não-progressiva (paralisia cerebral) (Figura 6). Tais dados apontam para o predomínio de pesquisas envolvendo crianças, com quadro clínico específico.

Quanto à autoria dos artigos em CSA (Tabela 3), praticamente apenas os docentes realizaram pesquisas envolvendo essa temática. Tal fato, ao evidenciar uma ausência de participação de discentes, tanto de pós-graduação quanto de graduação, no desenvolvimento de estudos acerca de tal temática, nos leva a formular a hipótese de que tal recurso não vem sendo priorizado nos diferentes níveis de formação do fonoaudiólogo. Ainda quanto à autoria dos artigos, chama atenção a participação de 5 psicólogos nessa produção, sinalizando para a pos- sibilidade de outras áreas terem maior tradição na produção de conhecimento em torno dessa temática. Com isso, sugere-se que a Fonoaudiologia poder dispor de conhecimentos teórico-práticos já sistematizados e a partir daí avançar na sua produção específica.

\section{CONCLUSÃO}

Embora a pesquisa evidencie pouca produção de conhecimento em CSA na Fonoaudiologia é importante ressaltar que esse recurso também é utilizado e objeto de estudo de áreas afins, razão pela qual os dados aqui apresentados não permitem concluir a baixa produção científica sobre CSA em nosso país. Para o delineamento de um panorama completo cerca da produção científica em CSA, faz-se necessário realizar estudos dessa natureza envolvendo outras áreas como, por exemplo, a Psicologia, a Terapia Ocupacional, Fisioterapia e a Educação Especial.

Se, diversas áreas têm papel importante no implemento de estudos em torno da CSA, ressaltase a importância de tal implemento no campo da Fonoaudiologia. Enfim, por ter como objeto de estudo e intervenção a linguagem, cabe a grupos de fonoaudiólogos assumirem o compromisso de elaborar procedimentos teórico-metodológicos que permitam aos sujeitos com severas limitações no desenvolvimento e uso da oralidade, constituíremse como interlocutores a partir de outras modalidades e formas de manifestação da linguagem.

\begin{abstract}
Background: speech therapy has been using the resources of Augmentative and Alternative Communication (AAC), allowing a greater autonomy of people with significant impairments in oral communication. This utilization has been expanding in Brazil, however it is still not a common practice among speech therapists. Purpose: to analyze knowledge production in AAC in Brazilian journals related to Speech Therapy. These journals were analyzed between 1997 and 2005. Conclusion: as AAC is a resource used in other academic fields, such data is not sufficient to conclude about knowledge production in AAC in general. Thus, in order to have a more complete overview in this field, the analysis of other academic fields is required, such as Pedagogy, Occupational Therapy, Physiotherapy, Psychology, among others.
\end{abstract}

KEYWORDS: Communication Aids for Disabled; Scientific Communication and Diffusion; Periodical Index 


\section{REFERÊNCIAS}

1. Campanatti-Ostiz $\mathrm{H}$, Andrade CRF, Barbosa MA. Considerações teóricas sobre a escolha de descritores na área de fonoaudiologia. Pró-Fono. 2003; 15(2):211-8.

2. Bufrem LS, Sorribas TV. Produção científica em Ciência da Informação: análise temática em artigos de revistas brasileiras. Perspect Ciênc Inf. 2007; 12(1):38-49.

3. Munhoz CMA, Massi G, Berberian AP, Giroto CRM, Guarinello AC. Análise da produção científica nacional fonoaudiológica acerca da linguagem escrita. Pró-Fono. 2007; 19(3):249-58.

4. Campanatti-Ostiz H, Andrade CRF. Periódicos nacionais em fonoaudiologia: caracterização estrutural. Rev Soc Bras Fonoaudiol. 2005; 10(3): 147-54.

5. Campanatti-Ostiz H, Andrade CRF. Periódicos nacionais em fonoaudiologia: caracterização de indicador de impacto. Pró-Fono. 2006; 18(1):99-110.

6. Russo ICP, Ferreira LP. Fonoaudiólogos doutores no Brasil: análise das teses segundo áreas de atuação e programas. Pró-Fono. 2004; 16(1):119-30.

7. Chun RYS. Comunicação suplementar e/ou alternativa: favorecimento da linguagem de um sujeito não falante. Pró-Fono. 2003; 15(1):55-64.

8. Panhan $H$. Fonoaudiologia e comunicação suplementar e/ou alternativa. In: Pastorello LM, Rocha ACO. Fonoaudiologia e linguagem oral: os práticos do diálogo. São Paulo: Revinter; 2006.p.154.

9. Reily L.Escola Inclusiva linguagem e mediação. São Paulo: Papirus; 2006.

10. Capovilla FC, Gonçalves MJ, Macedo EC, Duduchi M. Codificação de mensagens pictoideográficas em paralisia cerebral: participação de processos verbais. Rev Dist Comun. 1998; 9(2):261-91.

11. Capovilla FC, Nunes L, Macedo EC. Memória de trabalho no paralisado cerebral: Primazia, recência e consolidação. Rev Dist Comun. 1998; 9(2):293-323.

\section{RECEBIDO EM: 02/07/2008}

ACEITO EM: 26/05/2009

Endereço para correspondência:

Simone Krüger

Rua Professor Sydney Antonio Rangel Santos, 238

Curitiba - PR

CEP: 80710-250

E-mail: simonekrueger@ hotmail.com
12. Baddeley AD, Hitch GJ. Working memory. In: Bower GH. The psychology of learning and motivation. London: London Academic Press; 1974. p.20-60.

13. Capovilla FC, Thiers VO. Aprendendo símbolos Bliss via computador. Rev Dist Comun. 1998; 9(2): 352-72.

14. Fernandes AS, Guedes FCZ. Comunicação suplementar e alternativa: indicação para crianças portadoras de paralisia cerebral. Fono Atual. 1999; 3(10):16-9.

15. Johnson RM. The picture communication symbols guide. Solana Beach: Mayer \& Johnson Co; 1995.p.60.

16. Pires SCF, Limongi SCO. Introdução de comunicação suplementarem paciente com paralisia cerebral atetóide. Pró-Fono. 2002; 14(1):51-60.

17. Almeida MA, Piza MHM, Lamônica DAC. Adaptações do sistema de comunicação por troca de figuras no contexto escolar. Pró-Fono. 2005; 17(2):233-40.

18. Walter CCFA. A adaptação do sistema PECS de comunicação para o Brasil: uma comunicação alternativa para pessoas com autismo infantil. In: Marquezine MC, Almeida MA, Tanaka EDO, Mori NNR, Shimazaki EM, organizadores. Perspectivas multidiciplinares em educação especial. Londrina: Ed UEL. 1998. p.277-80.

19. Trevisor TT, Chun RYS. O desenvolvimento da linguagem por meio do sistema pictográfico de comunicação. Pró-Fono. 2004; 16(3):323-32.

20. Miranda CL, Gomes DCl. Contribuições da comunicação alternativa de baixa tecnologia em paralisia cerebral sem comunicação oral: relato de caso. Rev CEFAC. 2004; 6(3):247-52.

21. Capovilla FC, Macedo EC, Duduchi M, Capovilla AGS, Thiers VO. Sistemas de comunicação alternativa e suplementar: princípios de engenharia e design. Rev Dist Comun. 1998; 9(2):185-231.

22. Capovilla FC, Capovilla AGS, Macedo EC. $O$ uso de sistemas alternativos e facilitadores de comunicação nas afasias. Rev Dist Comun. 1998; 9(2):233-59.

23. Passos PMP. A construção da subjetividade através da interação dialógica pela comunicação suplementar e alternativa [dissertação]. Piracicaba (SP): Universidade Metodista de Piracicaba; 2007. 